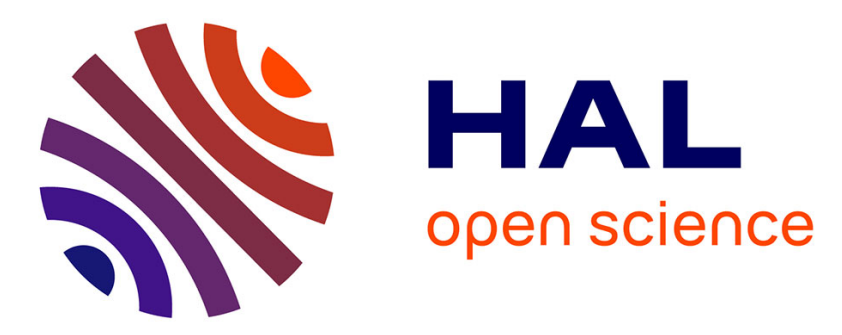

\title{
Carbon Diffusion and Kinetics During the Lath Martensite Formation
}

T.Y. Hsu (xu Zuyao)

\section{To cite this version:}

T.Y. Hsu (xu Zuyao). Carbon Diffusion and Kinetics During the Lath Martensite Formation. Journal de Physique IV Proceedings, 1995, 05 (C8), pp.C8-351-C8-354. 10.1051/jp4:1995851 . jpa-00254100

\section{HAL Id: jpa-00254100 https://hal.science/jpa-00254100}

Submitted on 1 Jan 1995

HAL is a multi-disciplinary open access archive for the deposit and dissemination of scientific research documents, whether they are published or not. The documents may come from teaching and research institutions in France or abroad, or from public or private research centers.
L'archive ouverte pluridisciplinaire HAL, est destinée au dépôt et à la diffusion de documents scientifiques de niveau recherche, publiés ou non, émanant des établissements d'enseignement et de recherche français ou étrangers, des laboratoires publics ou privés. 


\title{
Carbon Diffusion and Kinetics During the Lath Martensite Formation
}

\author{
T.Y. Hsu (Xu Zuyao) \\ Shanghai Jiao Tong University, Dept. Materials Science, Shanghai, 200030, China
}

\begin{abstract}
Calculations verify that carbon diffusion may occur during the lath martensite formation. Accordingly, the diffusion of interstitial atoms or ions must be taken into account when martensitic transfomation is defined as a diffusionless transformation. In derivation of the kinetics equation of the athermal martensitic transformation, regarding the carbon diffusion, $i$.e.the

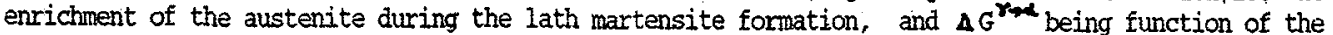
temperature and the carbon content in austenite, the kinetics ecquation is modified to a general form as:

$$
f=1-\exp \left[\beta\left(C_{1}-C_{0}\right)-\alpha(M s-T q)\right]
$$

where $C_{0}$ and $C_{1}$ are carbon contents in the austenite before and after quenching respectively. Consequently, the alloying element not only influences Ms, but also the diffusibility of carbon and both factors govern the amount of retained austenite in quenched steel which dominates in determing the toughness of the steel.
\end{abstract}

\section{CARBON DIFFUSION DURING THE FORMATION OF LATH MARTENSITE}

Rao and Thomas[1] found from high resolution TEM that in quenched steel with low or medium carbon the retained austenite is trapped between the lath martensite. Lattice images indicated substantial carbon enrichment of the retained austenite (from $0.27 \%$ to 0.4-1.048) at lath martensite/austenite interphase boundaries. Sarikaya et al[2] confirmed such an enrichment from transmission electron microscope(TEM), convergent beam electron diffraction(CBED) and field ion-atom probe (FIAP). Primary calculation[3] showed that in a quenched steel with $0.27 \% \mathrm{C}$, the time required for carbon diffusion from martensite to enrich the $\mathrm{H} / \mathrm{Y}$ boundary to $1.04 \% \mathrm{C}$, being $2 \times 10^{-4}$ to $10^{-7}$ sec, can keep pace with the formation of lath martensite, considering that carbon diffusion may be driven by the chemical potential resulting from the different solubility of carbon in martensite and ferrite. TEM experiments revealed a small amount of twinned martensite in a quenched $0.12 \mathrm{C}-$ - 0 w $\mathrm{Ni}$ and $\mathrm{Cr}$ steel[3]. The present author has pointed out that the diffusion of carbon may occur concomitantly with lath martensite formation, however, the formation mechanism of lath martensite is typically displacive and is not identical with that of bainite[3-5]. By solution of Fick's law for the case of diffusion in a plane sheet with uniform initial distribution and surface concentration for the carbon concentration profile as shown in Fig $1,21,=15 \times 10^{-6} \mathrm{~cm}, 2 I_{2}=1 \times 10^{-6} \mathrm{~cm}$, and $T=700 \mathrm{~K}$. Following the data in [1] and [2], the time required for the carbon diffusion to enrich the ratained austenite during the formation of lath martensite is calculated to be $7.25 \times 10^{-5}$ to $3 \times 10^{-6} \mathrm{sec}$ and that for the equalization of the enriched austenite to be $2 \times 10^{-2} \sec [4,5]$. 


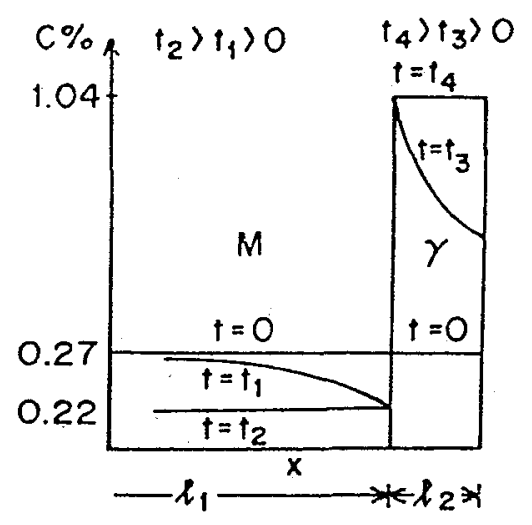

Figure 1: Sketch of carbon concentration profile in martensite( $M)$ and retained austenite in a quenched steel with $0.27 \% \mathrm{C}$

The time required for the carbon diffusion to enrich the interphase boundary dislocation to $1.048 \mathrm{C}$ during the growth of the lath martensite is calculated to be $3.2 \times 10^{-0^{-}}$$2.5 \times 10^{-7}$ sec, taking $\mathrm{T}=700 \mathrm{~K}$ and the dislocation density $=10^{-12} / \mathrm{cm}^{2}$. In comparison with the time for formation of a martensite lath from the experimental data of the growth rate of lath martensite, i.e. $10^{-3}-10^{-7} \mathrm{sec}$, the calculation. implies that carbon diffusion may keep pace with, or slightly lag behind, the formation of lath martensite. The time required for the equalization of the enriched austenite is at least one order of magnitude lower than the formation of lath martensite, implying that the carbon diffusion may occur, but is not a major, or necessary process in lath martensite transformation.

\section{DEFINITION OF A MARTENSITIC TRANSFORMATION}

Raferring the definitions of a martensitic transformation given by various authors from 1951 to 1990 as reviewed in the previous paper[6] and considering the carbon diffusion during the lath martensite formation as described in the previous section and also the fact that the formation of the isothermal martensite in the retainer austenite in a queched ball bearing steel with $1 \% \mathrm{C}$ and $1.5 \% \mathrm{Cr}$ is also driven by the carbon diffusion[7], the present author [6] has defined a martensite transformation as a first order, nucleation-growth transformation with shape change and surface relief characterized by an invariant plane strain as a result of the diffusionless shear displacement of substitutional atoms(ions). The displacement includes homogeneous and inhomogeneous shear. So, it seems better to add "homogeneous and inhomogeneous" before "shear displacement" in the above definition for modification. The characteristics of lath martensite formation are consistent with the definition given above and it is ideally martensitic.

\section{KINETICS OF ATHERMAL MARTENSITIC TRANSFORMATION}

Magee[8] has derived a kinetics equation for an athermal martensitic transformation as $f=1-\exp [-\alpha(M s-T q)]$

where $f$ stands the volume fraction of martensite formed, Tq the temperature of quenching medium and $\alpha$ refers a constant which depends on the composition of material. The experimental data for plain carbon steels with carbon content $0.37 \%$ to $1.10 \%$ given by Koistinen and Marburger [9] may serve as evidence in support of the above relationship taking $\alpha=1.10 \times 10^{-2}$. Although the average volume of martensite formed at different temperatures is not a constant as it is assumed in the derivation of equation (1), Magee's equation can express approximately the extent of an athermal martensitic transformation in steels with high or medium carbon content. As $\mathrm{Tg}$ is taken as room temperature, from equation(1), one may conclude that the higher the us, 
the lower will be the amount of the retained austenite,i.e. the amount of (1-f), which was taken to be a general rule for a long term:

In derivation of Magee's equation, the change in free energy per unit volume accompanying the martensitic transformation, $\Delta G$, is considerad to be a function of temperature only. However, during lath martensite formation, there may be carbon diffusion. Consequently, $\Delta G$ is a function of not only temperature but also the carbon content in austenite and Magee's equation should be modified. The present author and his co-workers[10] have derived a kinetics equation in general form, which applies even to low-carbon steels:

$$
f=1-\exp \left[\beta\left(C_{s}-C_{0}\right)-\alpha(M s-T q)\right]
$$

or the amount of the retained austenite, $f(\boldsymbol{\gamma})$ can be expressed as:

$$
f(\boldsymbol{\gamma})=1-f=\exp \left[\beta\left(C_{1}-C_{0}\right)-\alpha(M s-T q)\right]
$$

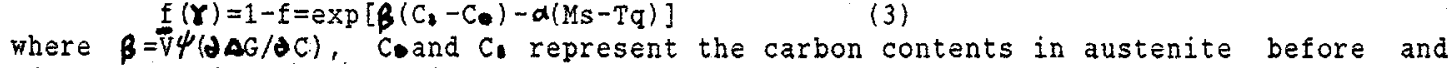
after quenching, respectively. Equation(3) is significant not only in expressing the extent of an athermal martensite formation but also in predicting the fracture toughness of quenched steels with a microstructure of lath martensite, since the amount of retained austenite governs the toughness parameter of the steel[11]. In high or mediun carbon steels, carbon diffusion will not occur during the martensitic transformation because $M s$ is too $I_{0}$. In this case, $C_{\mathbf{l}}=C_{0}$, and equation(2) reduces to equation(1).

Addition of alloying elements in steel affects not only Ms, but also the diffusion coefficent of carbon in martensite, and both factors determine the amount of retained. austenite. Manganese lowers $M s$ and slightly affects the diffusibility of carbon in steel. Thus, in steel containing $\mathrm{Mn}$, the amount of retained austenite increases moderately with the decrease of Ms. Nickel lowers Ms but raises the diffusibility of carbon in martensite, and accordingly in Ni-steel, the amount of the retained austenite increases rather drastically with the decrease of Ms. Strong carbide forming elements, such as niobium and rare earth element lower is too, but decrease the

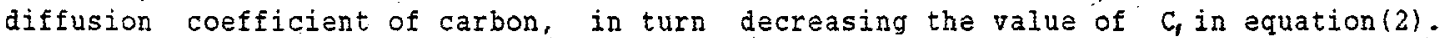
Addition of rare earth elements in a $0.27 \mathrm{C}-1 \mathrm{Cr}$ steel lower considerably the amount of the retained austenite in spite of lowering Ms[10]. According to the principle stated above, the effect of various alloying elements on the amount of the retained austenite in a quenched steel may be predicted[12]. Experimental results from the literaturs[10,11] confirm the prediction qualitatively and also verify equation(1).

\section{CONCLUSION}

Carbon diffusion may occur during the lath martensite formation. Accordingly; the diffusion of interstitial atoms or ions must be taken into account when a martensitic transformation is defined as a diffusionless transformation and Magee's equation expressing the kinetics of atheraml martensite formation should be modified as :

$$
f=1-\exp \left[\beta\left(C_{1}-C_{\bullet}\right)-\alpha(M s-T q)\right]
$$

where $C_{\text {. }}$ and $C_{\text {, }}$ are carbon contents in austenite before and after quenching, respectively. Experimental data from low carbon steels verify the above kinetics equation in general form. The modified equation is effective in application to lath martensite formation and in the case of steels with high or medium content of carbon, $C_{1}=C_{0}$. then the kinetics equation reduces to Magee's equation.

\section{References}

[1]Rao B.V.N.and Thomas G.,"Transmission electron microscopy characterization of dislocated lath martensite". International Conference on Martensitic Transformations, Cambridge Massachusetts 24-29 June 1979, Dept.Materials Science and Engineering. MIT Ed. (IIIT Press, Cambridge, 1979) pp.12-18.

[2] Sarikaya M. Thomas G. Steeds. J.W.et al, "Solute elements partitioning and austenite stabilization in steels", International Conference on Solid-solid Phase Transformations,Pittsburgh Pennsylvania 10-14 August 1981, H.I.Aaronson et al Eds.(TMS-AIME, Warrendale Pennsylvania 1982) pp.1421-1425.

[3] Hsu T.Y. (Xu ZuyaO) and Li X.,Acta MetaI1.Sin,19(1983)A83-88. 
[4] Hsu T.Y. (Xu Zuyao) and Li.X.,Acta Matal1.Sin,19(1983)A505-510.

[5]Hsu F.Y. (Xu Zuyao) and Li X., Scripta Metal1.17(1983)1285-1288.

[6] Hsu T.Y.(Xu.ZuYao), Acta Metal] Sin. (Chinese Edn), 27(1991)A161-172; (English Edn) ser. A4 (1991) 387-400.

[7] Hsu T.Y. (Xu Zuyao), Chen Y. and Chen W. MetaI1.Trans.18A (1987) 1389-1394.

[8] Magee C.L., Phase Transformations (Amer. Soc. Metals, Metals Park, Ohio, 1970) pp.115-156.

[9] Koistinen D.P. and Marburger R.E.,Acta Meta11.7(1959)59-10.

[10] Hsu T.Y. (Xu ZuYao), Lu W. and Wang Y., Iron and Steel (China), 30(1995) no.4,53-58.

[11]Rao B.V.N. and Thomas G. Metal1.Trans.11A(1980)441-457.

[12] Hsu T.Y. (Xu ZuYao), Shanghai Metals, (China), 17(1995) no.1,1-6. 